\title{
Change ratio of hemoglobin has predictive value for upper gastrointestinal bleeding
}

\author{
MINORU TOMIZAWA ${ }^{1}$, FUMINOBU SHINOZAKI ${ }^{2}$, RUMIKO HASEGAWA $^{3}$, YOSHINORI SHIRAI ${ }^{3}$, \\ YASUFUMI MOTOYOSHI ${ }^{4}$, TAKAO SUGIYAMA ${ }^{5}$, SHIGENORI YAMAMOTO ${ }^{6}$ and NAOKI ISHIGE ${ }^{7}$ \\ Departments of ${ }^{1}$ Gastroenterology, ${ }^{2}$ Radiology, ${ }^{3}$ Surgery, ${ }^{4}$ Neurology, ${ }^{5}$ Rheumatology, ${ }^{6}$ Pediatrics and \\ ${ }^{7}$ Neurosurgery, National Hospital Organization Shimoshizu Hospital, Yotsukaido, Chiba 284-0003, Japan
}

Received May 25, 2016; Accepted August 25, 2016

DOI: $10.3892 / b r .2016 .753$

\begin{abstract}
The present study aimed to identify novel predictors of upper gastrointestinal (GI) bleeding by assessing change ratios of blood test variables. Records of 1,023 patients (431 men and 592 women) who underwent endoscopy between October 2014 and September 2015 at the National Hospital Organization Shimoshizu Hospital (Yotsukaido, Japan) were retrospectively analyzed. Patients whose blood test variables for the time-point of endoscopy and three months previously were available were enrolled and subsequently categorized into a group with and another one without upper GI bleeding ( $n=32$ and 84, respectively), and the respective change ratios were calculated for each group. One-way analysis of variance revealed that in patients with upper GI bleeding, change ratios of white blood cell count and alkaline phosphatase were significantly higher than those in patients without, while change ratios of hemoglobin $(\mathrm{Hb})$, total protein and albumin were significantly reduced. Logistic regression analysis demonstrated that the change ratio of $\mathrm{Hb}$ was significantly correlated with upper GI bleeding. Receiver-operator characteristic analysis revealed that an $18.7 \%$ reduction of $\mathrm{Hb}$ was the threshold value for the prediction of upper GI bleeding. In conclusion, the present study revealed that a $\geq 18.7 \%$ reduction in $\mathrm{Hb}$ over three months has predictive value for upper GI bleeding.
\end{abstract}

\section{Introduction}

Upper gastrointestinal (GI) bleeding occurs proximal to the Treitz ligament and may be caused by gastric or duodenal ulcers or gastric cancer (1). The mortality rate of patients with

Correspondence to: Dr Minoru Tomizawa, Department of Gastroenterology, National Hospital Organization Shimoshizu Hospital, 934-5 Shikawatashi, Yotsukaido, Chiba 284-0003, Japan E-mail: nihminor-cib@umin.ac.jp

Key words: upper gastrointestinal bleeding, hemoglobin, logistic regression analysis, receiver-operator characteristics upper GI bleeding ranges from 3.5 to $7.4 \%(2,3)$. Upper GI bleeding is diagnosed by endoscopy (4). Upper GI bleeding is treated with endoscopy, such as clipping and bipolar electrocoagulation (4) However, for patients for whom endoscopic treatment fails, interventional radiology is applied $(5,6)$. The mortality rate rises to $40 \%$ when patients become hemodynamically unstable (7); therefore, it is important to predict upper GI bleeding prior to this.

The Glasgow Batchford Scores, Modified Early Waning Score and Pre-endoscopic Rockall scores are useful for stratification of patients with regard to unstable state, requirement of transfusion and hospitalization $(8,9)$. These scoring systems are useful for triage and management of upper GI bleeding (10). Analyses of on data from emergency departments or intensive care units identified malignancy, hypotension on admission, low Glasgow coma scale and kidney dysfunction as predictors of poor outcome (11). It would be beneficial to diagnose upper GI bleeding in patients prior to presentation at the emergency department. Moreover, certain patients with upper GI bleeding do not exhibit any symptoms (12). Therefore, it is desirable to diagnose upper GI bleeding prior to the advancement of affected patients to the unstable state.

As blood test variables are easy to obtain and reliable, the present study investigated the predictive value of their changes with regard to upper GI bleeding. The change ratios of blood test variables at the time-point of endoscopy and 3 months previously were evaluated.

\section{Materials and methods}

Ethics statement. The Ethics Committee of the National Hospital Organization Shimoshizu Hospital approved the present study, which was not assigned as a clinical trial because it was based on daily clinical practice. Patient records were anonymized and retrospectively analyzed. Written informed consent was obtained from all patients who were subjected to endoscopy.

Patients. Between October 2014 and September 2015, a total of 1,023 patients were subjected to endoscopy at the National Hospital Organization Shimoshizu Hospital (Yotsukaido, Japan). Endoscopy was indicated due to anemia, tarry stool or abdominal pain, or was performed for screening 
Table I. Indications for assessment of upper GI bleeding by endoscopy.

\begin{tabular}{lcc}
\hline Symptom & All patients (n) & $\begin{array}{c}\text { Patients with bleeding/ } \\
\text { no bleeding, }(\%)\end{array}$ \\
\hline Anemia & 9 & $5 / 4(15.6 / 4.8)$ \\
Hematemesis & 5 & $4 / 1(12.5 / 1.2)$ \\
Tarry stool & 8 & $7 / 1(21.9 / 1.2)$ \\
Others $^{\mathrm{a}}$ & 94 & $16 / 78(50 / 92.8)$ \\
Total & 116 & $32 / 84(100 / 100)$ \\
\hline
\end{tabular}

Bleeding was diagnosed by endoscopy and in positive patients, colonoscopy was performed within one month after endoscopy. ${ }^{\text {ancluded }}$ patients undergoing screening $(n=47,49.5 \%)$.

Table II. Causes of upper gastrointestinal bleeding.

\begin{tabular}{lc}
\hline Cause & No. of patients \\
\hline Gastric ulcer & 17 \\
Gastric cancer & 4 \\
Hemorrhagic gastritis & 4 \\
Reflux esophagitis & 3 \\
Duodenal ulcer & 2 \\
Acute gastric mucosal lesion & 1 \\
Esophageal varices & 1 \\
Total & 32 \\
\hline
\end{tabular}

purposes (Table I). From these subjects, patients whose blood test variables at the time-point of endoscopy and three months previously were available were enrolled in the present study. For these patients, change ratios of blood test variables between these two time-points were evaluated. The group with upper GI bleeding $(\mathrm{n}=32)$ comprised 15 males and 17 females (mean age, 69.3 \pm 12.9 ), while the group without upper GI bleeding $(n=84)$ comprised 37 males and 47 females

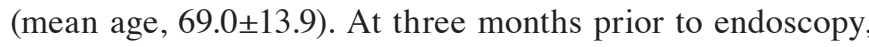
the presence of upper GI bleeding was not known for any of the patients. Colonoscopy was not performed for patients who were negative for bleeding on endoscopy.

Endoscopy. The devices GIF-N260H, GIF-XP260NS, GIF-PfG260, GIF-XQ260 and GIF-Q260 (Olympus, Tokyo, Japan) were used for endoscopy. Bleeding from a gastric or duodenal ulcer was restricted to a spurting vessel, an oozing vessel, a visible vessel or a clot, according to the Forrest classification system (13). In Table II the diagnoses of the patients are listed.

Blood test variables. The following blood test variables were analyzed: White blood cell count (WBC), hemoglobin ( $\mathrm{Hb}$ ), platelet count, C-reactive protein, total protein (TP), albumin (Alb), alkaline phosphatase, aspartate aminotransferase, alanine aminotransferase (ALT), gamma-glutamyl transpeptidase, lactate dehydrogenase, uric acid, blood urea nitrogen (BUN),
Table III. Comparison of change ratios of blood test variables between patients with and without upper gastrointestinal bleeding.

\begin{tabular}{lccr}
\hline & \multicolumn{2}{c}{$\begin{array}{c}\text { Upper gastrointestinal } \\
\text { bleeding }\end{array}$} \\
\cline { 2 - 3 } Characteristic/parameter & $(-)$ & $(+)$ & P-value \\
\hline Gender (male/female), n & $37 / 47$ & $15 / 17$ & \\
Mean age, years & $69.0 \pm 13.9$ & $69.3 \pm 12.9$ & 0.983 \\
WBC & $1.02 \pm 0.29$ & $1.23 \pm 0.64$ & 0.050 \\
Hb & $0.97 \pm 0.15$ & $0.75 \pm 0.23$ & $<0.001$ \\
Plt & $2.69 \pm 12.8$ & $1.32 \pm 0.52$ & 0.663 \\
CRP & $2.62 \pm 3.69$ & $15.5 \pm 5.95$ & 0.074 \\
TP & $0.99 \pm 0.10$ & $0.84 \pm 0.16$ & $<0.001$ \\
Alb & $0.97 \pm 0.12$ & $0.81 \pm 0.21$ & 0.010 \\
ALP & $1.02 \pm 0.20$ & $0.74 \pm 0.19$ & 0.006 \\
AST & $1.13 \pm 0.68$ & $1.74 \pm 1.92$ & 0.056 \\
ALT & $1.14 \pm 0.51$ & $1.94 \pm 2.72$ & 0.037 \\
$\gamma$-GTP & $1.20 \pm 0.73$ & $2.55 \pm 4.25$ & 0.134 \\
LDH & $1.02 \pm 0.43$ & $1.01 \pm 0.35$ & 0.946 \\
UA & $0.98 \pm 0.13$ & $1.04 \pm 0.37$ & 0.420 \\
BUN & $0.96 \pm 0.33$ & $1.02 \pm 0.73$ & 0.739 \\
TG & $0.94 \pm 0.50$ & $1.61 \pm 1.00$ & 0.051 \\
HDL & $1.08 \pm 0.46$ & $0.90 \pm 0.12$ & 0.443 \\
LDL & $1.02 \pm 0.32$ & $0.93 \pm 0.22$ & 0.519 \\
BG & $0.92 \pm 0.17$ & $1.40 \pm 1.12$ & 0.056 \\
HbA1c & $0.94 \pm 0.11$ & $1.03 \pm 0.11$ & 0.345 \\
\hline
\end{tabular}

WBC, white blood cell count; Hb, hemoglobin; Plt, platelets; CRP, C-reactive protein; TP, total protein; Alb, albumin; ALP, alkaline phosphatase; AST, aspartate aminotransferase; ALT, alanine aminotransferase; $\gamma$-GTP, $\gamma$-glutamyl transpeptidase; LDH, lactate dehydrogenase; UA, uric acid; BUN, blood urea nitrogen; TG, triglyceride; HDL, high-density lipoprotein cholesterol; LDL, low-density lipoprotein cholesterol; BG, blood glucose; HbA1c, hemoglobin Alc.

Table IV. Results of the logistic regression analysis.

\begin{tabular}{lcc}
\hline Parameter & Odds ratio & P-value \\
\hline $\mathrm{WBC}$ & $1.056 \mathrm{xe} 8$ & 0.999 \\
$\mathrm{Hb}$ & $8.13 \times \mathrm{xe} 23$ & 0.017 \\
$\mathrm{TP}$ & $7.74 \times \mathrm{xe}-14$ & 0.999 \\
$\mathrm{Alb}$ & $4.36 \mathrm{xe} 9$ & 0.999 \\
$\mathrm{ALP}$ & $9.77 \times \mathrm{xe}-11$ & 0.999 \\
\hline
\end{tabular}

e, Napier's constant of natural logarithm (2.71828); WBC, white blood cell count; Hb, hemoglobin; TP, total protein; Alb, albumin; ALP, alkaline phosphatase.

triglyceride, high-density lipoprotein cholesterol, low-density lipoprotein cholesterol, blood glucose and hemoglobin Alc. Change ratios were calculated using the following equation: 

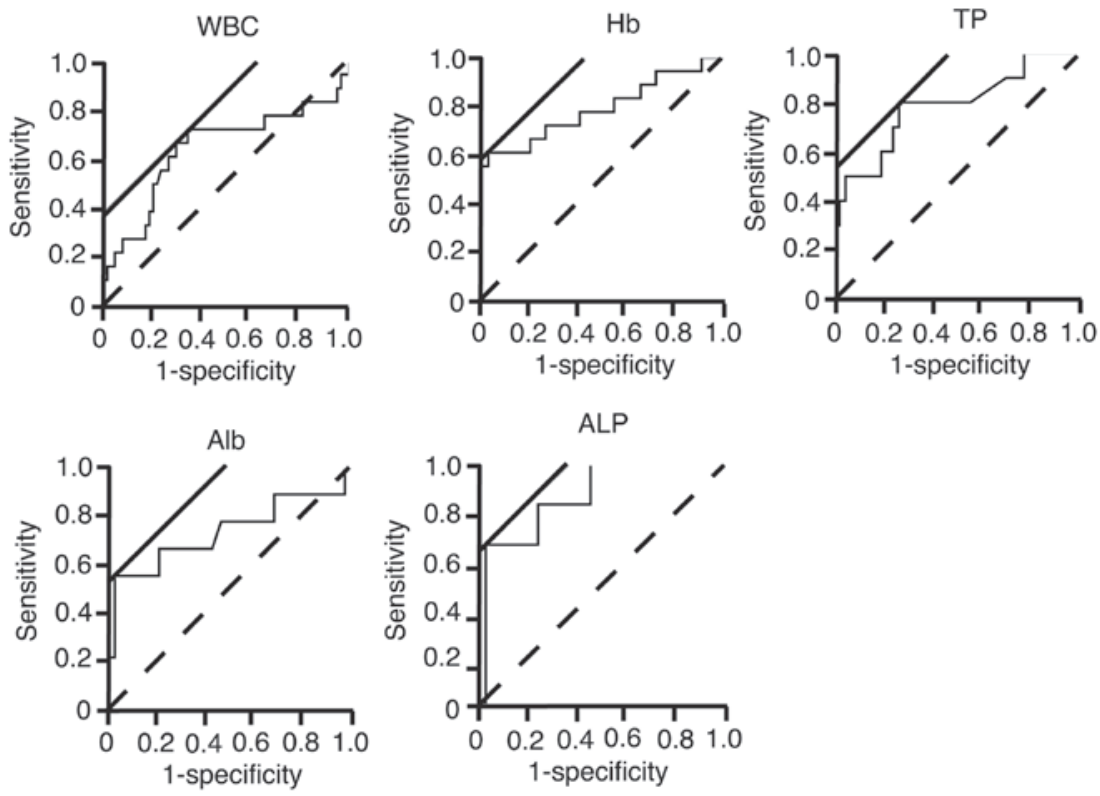

Figure 1. Receiver-operator characteristic analysis was performed to determine a threshold value for the prediction of upper gastrointestinal bleeding using the change ratio of WBC, Hb, TP, Alb and ALP. Threshold values were determined as values that was in contact with the line with an increment of $45^{\circ}$ (solid straight line) and had the greatest distance from the reference line (broken line). WBC, white blood cell count; Hb, hemoglobin; TP, total protein; Alb, albumin; ALP, alkaline phosphatase.

(result at 3 months prior to endoscopy - result on the date of endoscopy)/result at 3 months prior to endoscopy.

Statistical analysis. One-way analysis of variance was applied to compare change ratios between patients with and without upper GI bleeding. Logistic regression analysis was applied to identify blood test variables whose change ratios were significantly associated with upper GI bleeding. Receiver-operator characteristic (ROC) analysis was used to determine threshold values for the prediction of upper GI bleeding. $\mathrm{P}<0.05$ was considered to indicate a statistically significant difference. JMP 10.0.2 (SAS Institute, Inc., Cary, NC, USA) was used to perform statistical analyses.

\section{Results}

To identify blood test parameters whose changes were significantly associated with upper GI bleeding, change ratios were compared between patients without or with upper GI bleeding using one-way analysis of variance (Table III). The change ratios of WBC $(\mathrm{P}=0.05)$ and ALT $(\mathrm{P}=0.037)$ in patients with upper GI bleeding were higher were higher than in patients without bleeding. Furthermore, the change ratios of $\mathrm{Hb}(\mathrm{P}<0.001), \mathrm{TP}$ $(\mathrm{P}<0.001)$ and Alb $(\mathrm{P}=0.01)$ in patients with upper GI bleeding were lower that in those without bleeding. These results suggested that the change ratios of $\mathrm{WBC}, \mathrm{Hb}, \mathrm{TP}, \mathrm{Alb}$ and ALT were significantly associated with upper GI bleeding.

Logistic regression analysis was performed to identify blood test variables with change ratios that were strongly associated with upper GI bleeding (Table IV). The change ratio of $\mathrm{Hb}$ was determined to be significantly associated with upper GI bleeding $(\mathrm{P}=0.017)$; whereas no significant correlation was identified for the change ratios of the remaining blood test variables with $\mathrm{P}$-values close to 1 . These results suggested that the change ratio of $\mathrm{Hb}$ was significantly correlated with upper GI bleeding.
Table V. Variables with receiver-operator characteristics.

\begin{tabular}{lcccc}
\hline Parameter & $\begin{array}{c}\text { Area under } \\
\text { curve }\end{array}$ & $\begin{array}{c}\text { Threshold } \\
\text { value }\end{array}$ & $\begin{array}{c}\text { Sensitivity } \\
(\%)\end{array}$ & $\begin{array}{c}\text { Specificity } \\
(\%)\end{array}$ \\
\hline WBC & 0.634 & 1.047 & 72.2 & 64.6 \\
$\mathrm{Hb}$ & 0.780 & 0.813 & 61.1 & 95.4 \\
$\mathrm{TP}$ & 0.780 & 0.952 & 80.0 & 73.2 \\
$\mathrm{Alb}$ & 0.732 & 0.771 & 55.6 & 96.6 \\
$\mathrm{ALP}$ & 0.854 & 0.759 & 66.7 & 95.8 \\
\hline
\end{tabular}

Values are stated as change ratios. WBC, white blood cell count; $\mathrm{Hb}$, hemoglobin; TP, total protein; Alb, albumin; ALP, alkaline phosphatase.

ROC analysis was performed to determine the threshold values of change ratios for the prediction of upper GI bleeding (Fig. 1). A threshold value was determined as a value that was in contact with the line with an increment of $45^{\circ}$ (Fig. 1, solid straight line) and had the greatest distance from the reference line (Fig. 1, broken line). Variables obtained via ROC analysis are presented in Table V. The threshold value of the change ratio of $\mathrm{Hb}$ was 0.813 , which was converted into the threshold of the change rate using the following formula: (1.000-0.813) x $100 \%=18.7 \%$. Therefore, a $18.7 \%$ reduction of $\mathrm{Hb}$ over three months was the threshold value for the prediction of upper GI bleeding.

\section{Discussion}

To date, only a limited number of studies have assessed the association of change ratios of blood test variables with upper GI bleeding. It has been previously demonstrated that 
the change ratio of the Model for End-Stage Liver Disease score is useful for the prediction of bleeding from esophageal varices (14); however, this model is applicable to patients with liver cirrhosis only and was therefore not used in the present study.

Decreased $\mathrm{Hb}$ has been previously reported to be associated with upper GI bleeding (15). However, a limitation with regard to evaluation of $\mathrm{Hb}$ is that results differ between first-time and repeated sampling (16). Hb below the normal range indicates upper GI bleeding. The present study further assessed the predictive value of the change ratio of blood parameters with regard to upper GI bleeding. In a previous study by our group, a $21.3 \%$ reduction of $\mathrm{Hb}$ within 3 months was determined to be the threshold value for the prediction of upper GI bleeding (17). In line with this, an $18.7 \%$ reduction was determined to be the threshold value for the prediction of upper GI bleeding in the present study. Although the patient cohorts were totally different between the two studies, the threshold was $\sim 20 \%$ in each, suggesting that a change ratio of $\mathrm{Hb}$ of $\sim 20 \%$ or above is of predictive value regarding upper GI bleeding.

A limitation of the present study was the difficulty in differentiating between upper and lower GI bleeding, which may have affected the assessment of the association of the change ratio of $\mathrm{Hb}$ with upper GI bleeding (18). To differentiate between upper and lower GI bleeding, an elevated BUN value may be useful (19), as higher BUN indicates severe upper GI bleeding (20). In the present study, BUN was not significantly different between patients with or without upper GI bleeding. This result may suggest that upper GI bleeding was not very severe in the patients.

In conclusion, an $18.7 \%$ reduction of $\mathrm{Hb}$ over three months was shown to be associated with upper GI bleeding in the present study. These findings suggested that patients with this change ratio of $\mathrm{Hb}$ are at risk of upper GI bleeding. It is recommended that patients are subjected to endoscopic examination if presenting with symptoms of upper GI bleeding and $\mathrm{Hb}$ levels lowered by $\geq 20 \%$.

\section{References}

1. Theocharis GJ, Thomopoulos KC, Sakellaropoulos G, Katsakoulis E and Nikolopoulou V: Changing trends in the epidemiology and clinical outcome of acute upper gastrointestinal bleeding in a defined geographical area in Greece. J Clin Gastroenterol 42: 128-133, 2008

2. Hearnshaw SA, Logan RF, Lowe D, Travis SP, Murphy MF and Palmer KR: Acute upper gastrointestinal bleeding in the UK: Patient characteristics, diagnoses and outcomes in the 2007 UK audit. Gut 60: 1327-1335, 2011.

3. Leontiadis GI, Molloy-Bland M, Moayyedi P and Howden CW: Effect of comorbidity on mortality in patients with peptic ulcer bleeding: Systematic review and meta-analysis. Am J Gastroenterol 108: 331-345, quiz 346, 2013.
4. Kim SY, Hyun JJ, Jung SW and Lee SW: Management of non-variceal upper gastrointestinal bleeding. Clin Endosc 45: 220-223, 2012

5. Wilkins T, Khan N, Nabh A and Schade RR: Diagnosis and management of upper gastrointestinal bleeding. Am Fam Physician 85: 469-476, 2012.

6. Katano T, Mizoshita T, Senoo K, Sobue S, Takada H, Sakamoto T, Mochiduki H, Ozeki T, Kato A, Matsunami K, et al: The efficacy of transcatheter arterial embolization as the first-choice treatment after failure of endoscopic hemostasis and endoscopic treatment resistance factors. Dig Endosc 24: 364-369, 2012.

7. Walsh RM, Anain $\mathrm{P}$, Geisinger $\mathrm{M}$, Vogt $\mathrm{D}$, Mayes $\mathrm{J}$, Grundfest-Broniatowski S and Henderson JM: Role of angiography and embolization for massive gastroduodenal hemorrhage. J Gastrointest Surg 3: 61-65, discussion 66, 1999.

8. Bozkurt S, Köse A, Arslan ED, Erdoğan S, Üçbilek E, Çevik İ, Ayrık C and Sezgin O: Validity of modified early warning, Glasgow Blatchford, and pre-endoscopic Rockall scores in predicting prognosis of patients presenting to emergency department with upper gastrointestinal bleeding. Scand J Trauma Resusc Emerg Med 23: 109, 2015.

9. Thanapirom K, Ridtitid W, Rerknimitr R, Thungsuk R, Noophun P, Wongjitrat C, Luangjaru S, Vedkijkul P, Lertkupinit C, Poonsab S, et al: Prospective comparison of three risk scoring systems in non-variceal and variceal upper gastrointestinal bleeding. J Gastroenterol Hepatol 31: 761-767, 2016.

10. Rahman SH, Larvin M, McMahon MJ and Thompson D: Clinical presentation and delayed treatment of cholangitis in older people. Dig Dis Sci 50: 2207-2210, 2005

11. Kaya E, Karaca MA, Aldemir D and Ozmen MM: Predictors of poor outcome in gastrointestinal bleeding in emergency department. World J Gastroenterol 22: 4219-4225, 2016.

12. Bini EJ, Rajapaksa RC, Valdes MT and Weinshel EH: Is upper gastrointestinal endoscopy indicated in asymptomatic patients with a positive fecal occult blood test and negative colonoscopy? Am J Med 106: 613-618, 1999.

13. Forrest JA, Finlayson ND and Shearman DJ: Endoscopy in gastrointestinal bleeding. Lancet 2: 394-397, 1974.

14. Xu XD, Dai JJ, Qian JQ, Pin X and Wang WJ: New index to predict esophageal variceal bleeding in cirrhotic patients. World J Gastroenterol 20: 6989-6994, 2014.

15. Gralnek IM, Dumonceau JM, Kuipers EJ, Lanas A, Sanders DS, Kurien M, Rotondano G,Hucl T, Dinis-Ribeiro M, Marmo R, et al: Diagnosis and management of nonvariceal upper gastrointestinal hemorrhage: European Society of Gastrointestinal Endoscopy (ESGE) Guideline. Endoscopy 47: a1-a46, 2015.

16. McFarlane A, Aslan B, Raby A, Bourner G and Padmore R: Critical values in hematology. Int J Lab Hematol 37: 36-43, 2015.

17. Tomizawa M, Shinozaki F, Hasegawa R, Togawa A, Shirai Y, Ichiki N, Motoyoshi Y, Sugiyama T, Yamamoto S and Sueishi M: Reduced hemoglobin and increased C-reactive protein are associated with upper gastrointestinal bleeding. World J Gastroenterol 20: 1311-1317, 2014.

18. Chong V, Hill AG and MacCormick AD: Accurate triage of lower gastrointestinal bleed (LGIB) - A cohort study. Int J Surg 25: 19-23, 2016.

19. Tomizawa M, Shinozaki F, Hasegawa R, Shirai Y, Motoyoshi Y, Sugiyama T, Yamamoto $\mathrm{S}$ and Ishige N: Laboratory test variables useful for distinguishing upper from lower gastrointestinal bleeding. World J Gastroenterol 21: 6246-6251, 2015.

20. Tomizawa M, Shinozaki F, Hasegawa R, Shirai Y, Motoyoshi Y, Sugiyama T, Yamamoto S and Ishige N: Patient characteristics with high or low blood urea nitrogen in upper gastrointestinal bleeding. World J Gastroenterol 21: 7500-7505, 2015. 